\title{
Super-low friction of ta-C coating in presence of oleic acid
}

\author{
Makoto KANO $^{1}$, Jean Michel MARTIN ${ }^{2, *}$, Kentaro YOSHIDA ${ }^{1}$, Maria Isabel DE BARROS BOUCHET ${ }^{2}$ \\ ${ }^{1}$ Division of Mechanical \& Material Engineering, Kanagawa Industrial Technology Center 705-1 Shimo-Imaizumi, Ebina, Kanagawa, Japan \\ ${ }^{2}$ LTDS, Ecole Centrale de Lyon 69380, Ecully, France \\ Received: 12 December 2013 / Revised: 15 March 2014 / Accepted: 27 March 2014 \\ (C) The author(s) 2014. This article is published with open access at Springerlink.com
}

\begin{abstract}
Friction tests have been carried out on bearing steel friction pairs coated with a-C:H and ta-C under lubricated conditions with 1-hexadecene and pure oleic acid, respectively. Main results show that ta-C leads to the super-low regime with oleic acid (friction coefficient below 0.01) and that a-C:H is quite well lubricated by 1-hexadecen. Surface analyses by coupling X-ray photoelectron spectroscopy (XPS) and secondary ion mass spectrometry (SIMS) have been carried out in the case of oleic acid with ta-C and a-C:H coatings. Results show that tribochemical reactions have occurred. $\mathrm{OH}$ groups terminate the ta- $\mathrm{C}$ surface whereas a-C:H is covered by a thin tribofilm and is terminated by oleic acid monolayers. The superlow regime in the case of ta-C is mainly attributed to the presence of the $\mathrm{OH}$-termination.
\end{abstract}

Keywords: epoxy composite; short carbon fiber; friction; wear

\section{Introduction}

Reduction of energy loss by mechanical friction especially for automotive engine has been strongly required in recent years for improving fuel economy. Since a diamond-like carbon (DLC) coating has several advantages such as the low friction property, superior wear resistance, superior corrosion resistance and so on, the DLC coated application increases in the wide kinds of industries. Although the super low friction property below 0.01 of the friction coefficient is the most outstanding advantage of DLC coatings in vacuum or inert gas [1,2], there is no successfully actual application using this property except the applied technology for the following engine parts. A DLC-coated valve lifter and piston ring have been applied already to the actual mass-produced gasoline engines to reduce engine friction in Japan [1, 3]. This low friction property was obtained by the hydrogenfree DLC, (ta-C) lubricated by an ester containing gasoline engine oil [2]. Additionally, the ultra-low friction properties using ta-C were also obtained

* Corresponding author: Jean Michel MARTIN.

E-mail: jean-michel.martin@ec-lyon.fr under glycerol and oleic acid lubrication although the hydrogenated DLC, (a-C:H) did not show such a low friction properties [4-7].

Although in these previous papers, the tribochemical reactions leading to the functional group such as $-\mathrm{OH}$ and $-\mathrm{COOH}$ on the sliding surface of ta-C and a-C:H have been discussed, the way in which the tribofilm was built is not still made clear. Additionally, even the difference of the tribofilm composition between the DLCs is not shown. The objective of this study is to find a trigger to make clear the tribofilm chemistry and superlow friction mechanism under the selected lubricants by evaluating the friction of self-mated DLC and conducting X-ray photoelectron spectroscopy (XPS) and secondary ion mass spectrometry (SIMS) surface analyses.

\section{Test method}

The unidirectional rotating cylinder-on-disc sliding test was conducted in the following way. The cylinders, measuring $9 \mathrm{~mm}$ in diameter and $9 \mathrm{~mm}$ in length, were made of hardened bearing steel (AISI52100) and were polished in order to obtain a surface roughness 
$\mathrm{Rq}$ of about $15 \mathrm{~nm}$ (root mean square roughness). The $3 \mathrm{~mm}$ thick disc (33 $\mathrm{mm}$ in diameter) was also made of AISI52100 steel and was polished to a surface roughness Rq below $5 \mathrm{~nm}$. Two kinds of DLC were deposited on both discs and cylinders. The 1 micron thick a-C:H coating was obtained by plasma enhanced chemical vapor deposition (CVD) and the ta-C coating was obtained by the T-filtered arc physical vapor deposition (PVD) method [8] with a thickness of 0.3 micron. The a-C:H coating contains about 20 at $\%$ hydrogen measured by elastic recoil detection analysis (ERDA) and a hardness and Young's modulus of about $20 \mathrm{GPa}$ and $190 \mathrm{GPa}$, respectively. On the other hand, the ta-C coating which is produced by a new coating process has a very smooth surface without any droplet with a roughness comparable to that of a-C:H. It also has very high hardness and Young's modulus of $60 \mathrm{GPa}$ and $650 \mathrm{GPa}$, respectively measured by nanoindentation. The main properties of these DLC coatings are shown in Table1.

Two kinds of lubricant were selected to make clear the effect of the functional group on the friction property. One was 1-hexadecene $\left(\mathrm{C}_{16} \mathrm{H}_{32}\right)$ without any functional and polar group and the other was oleic acid $\left(\mathrm{C}_{18} \mathrm{H}_{34} \mathrm{O}_{2}\right)$ that contains the carboxylic group $-\mathrm{COOH}$ at the extremity. Viscosity at $296 \mathrm{~K}$ was 3.0 and $33.0 \mathrm{mPa} \cdot \mathrm{s}$ for 1-hexadecen and oleic acid, respectively. It is interesting to notice that both lubricants have almost the same number of carbon atoms in the skeleton of the molecule and possess one carbon double bond inside the carbon chain.

The cylinder was fixed in order to prevent it from rotating and was pressed against the rotating disc, as shown in Fig. 1. Contact at the sliding interfaces was ideally in the shape of lines under Hertzian pressure

Table 1 Main properties of DLC coatings.

\begin{tabular}{lccc}
\hline & $\begin{array}{c}\text { Steel } \\
\text { (uncoated) }\end{array}$ & a-C:H & ta-C \\
\hline Coating method & & PACVD & PVD filtered \\
Coating thickness $(\mu \mathrm{m})$ & & 1.1 & 0.3 \\
Disc roughness Rq $(\mathrm{nm})$ & 2.6 & 4.2 & 3.7 \\
Cylinder Rq $(\mathrm{nm})$ & 12 & 14.4 & 16.1 \\
Surface hardness $(\mathrm{GPa})$ & 10 & 20 & 61 \\
Young modulus $(\mathrm{GPa})$ & 200 & 190 & 650 \\
\hline
\end{tabular}

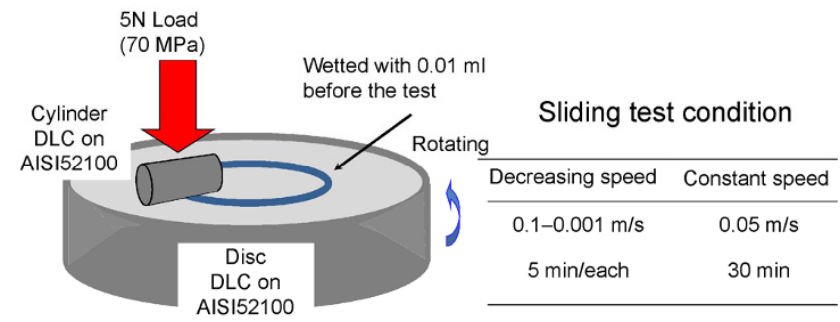

Fig. 1 Cylinder-on-disc sliding test.

of around $70 \mathrm{MPa}$. However, because there is never perfect linear conformal contact between the cylinder and the disc plate on the whole length, real contact occurs only on certain parts where pressure is certainly much higher than $70 \mathrm{MPa}$. In our case this pressure peaks are located at the two edges of the undulation of the cylinder side and this will be shown later in more details in the analytical part. Before starting to slide, a few droplets $(0.01 \mathrm{ml})$ of the lubricant were provided by gently wetting the disc. This lubricant quantity is enough to form a visible meniscus between the cylinder and the flat and can feed the contact area in good conditions. Moreover, this permits to observe the wetting of the residual lubricant in the wear scar at the end of the test. Temperature of the whole system was fixed at ambient temperature $\left(25^{\circ} \mathrm{C}\right)$ and the test is performed in ambient air (50\% RH).

First, a "decreasing speed test" was performed. The speed was progressively reduced step by step from $100 \mathrm{~mm} / \mathrm{s}$ to $0.01 \mathrm{~mm} / \mathrm{s}$, with holding for 5 minutes at each speed. This way of decreasing speed was designed to keep the smooth surface on the sliding track initially by starting to slide from the mild conditions towards the mixed lubrication regime. The results are expected to make clear the different friction properties between a-C:H and ta- $\mathrm{C}$ coatings according to the sliding speed and the two lubricants used.

Second, using new friction pairs, the "constant sliding speed test" was conducted to focus on tribofilm formation when the superlow friction regime was reached. The sliding test was conducted at $50 \mathrm{~mm} / \mathrm{s}$ for 30 minutes under oleic acid lubrication to investigate the difference in tribofilm chemistry on the sliding tracks for a-C:H and ta-C discs. XPS analyses were performed and oleic acid with deuterated carboxylic functional group was used to find some evidence of tribochemical reactions by ToF-SIMS. 


\section{Results and discussion}

\subsection{Friction properties in the "decreasing sliding speed" tests}

Figure 2 compares friction results of DLCs and steel surfaces lubricated by 1-hexadecene and oleic acid, and this during decreasing sliding speed tests from $100 \mathrm{~mm} / \mathrm{s}$ to $0.01 \mathrm{~mm} / \mathrm{s}$. These results have a shape of a Stribeck curve showing the different regimes that are encountered, namely elasto-hydrodynamic lubrication (EHL) above $100 \mathrm{~mm} / \mathrm{s}$, boundary lubrication (BL) under $1 \mathrm{~mm} / \mathrm{s}$ and mixed between these two speeds.

For steel surfaces, friction in the presence of 1-hexadecene was much higher than those with DLCs and increased largely above 0.3 when decreasing sliding speed below $1 \mathrm{~mm} / \mathrm{s}$. Therefore, the sliding test for the steel was definitely stopped at this speed. For oleic acid, the different friction coefficients of DLCs below $5 \mathrm{~mm} / \mathrm{s}$ seemed to be caused under boundary lubrication condition whereas those above $50 \mathrm{~mm} / \mathrm{s}$ seemed to be caused under the EHL lubrication regime. The friction coefficient under 1-hexadecene lubrication for ta-C(T) below $1 \mathrm{~mm} / \mathrm{s}$ was much higher than that for a-C:H. At the opposite, friction coefficient for ta-C(T) above $50 \mathrm{~mm} / \mathrm{s}$ was much lower than that for a-C:H (in the EHL regime).

For oleic acid lubrication, the friction coefficients for all friction pairs decreased significantly compared with those in presence of 1-hexadecene. Especially, the friction coefficient under oleic acid lubrication for ta-C(T) below $1 \mathrm{~mm} / \mathrm{s}$ and above $50 \mathrm{~mm} / \mathrm{s}$ was much lower than that for both a-C:H and steel combinations. It was found that the effect of reducing friction for ta- $\mathrm{C}$ in the presence of the carboxylic group $\mathrm{COOH}-$ was much stronger than for a-C:H. Additionally, for ta-C, the friction curve under oleic acid lubrication was much different from that under 1-hexadecene lubrication. Judging from these results, the ultra-low friction coefficient for ta- $\mathrm{C}$ under the sliding condition with oleic acid lubrication below $1 \mathrm{~mm} / \mathrm{s}$ sliding speed belongs to the boundary lubrication regime and seemed to be caused by the formation of a very low shear strength tribofilm. Alternatively, a-C:H coatings are better lubricated by hydrocarbons (alkanes or alkenes) with no oxygen-containing functions. Briefly, it is suggested that a-C:H is well lubricated by $\mathrm{H}$-containing lubricants whereas ta-C prefers $\mathrm{OH}-$ containing lubricants to reduce friction.

On the other hand, the super-low friction coefficient of around 0.005 for ta-C above $50 \mathrm{~mm} / \mathrm{s}$ sliding speed belongs to the very thin-film EHL lubrication regime and is certainly caused by another mechanism. An estimation of the maximum film thickness using Dowson's equation gives a value of $15 \mathrm{~nm}$, and a lambda ratio of 4 . One possible mechanism is that the ratio of fluid lubrication should increase drastically
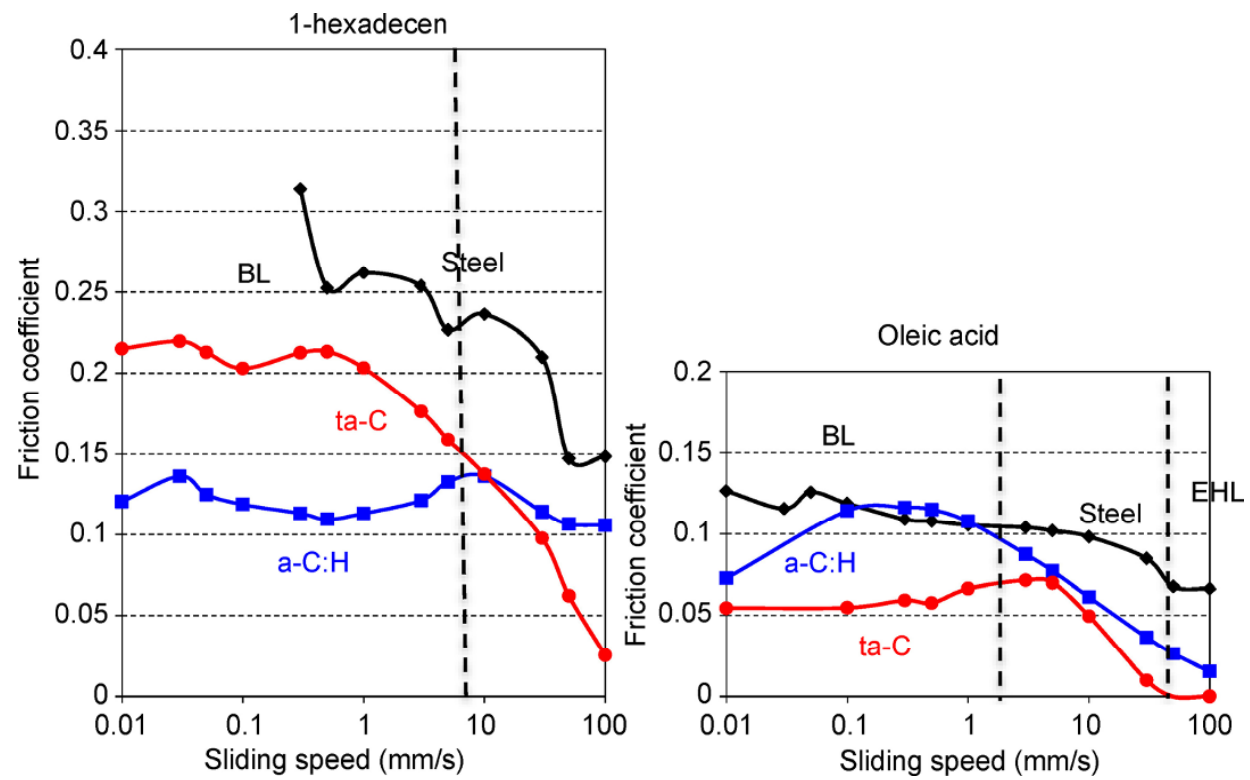

Fig. 2 Friction results of decreasing sliding speed tests (ambiant temperature). 
by improving wettability and possibly slip at the wall may occur.

\subsection{Friction properties of "constant sliding speed" tests}

Constant speed sliding tests were conducted twice for ta-C and a-C:H under deuterated oleic acid $\left(\mathrm{C}_{18} \mathrm{H}_{33}{ }^{2} \mathrm{H}_{1} \mathrm{O}_{2}\right)$ lubrication for 30 minutes in order to obtain two similar samples for analysis under the same sliding conditions. For ta-C (see Fig. 3), the friction coefficient decreased after only 60 seconds and is well below 0.01 and the regime was kept to around 0.005 in average value for at least $1,800 \mathrm{~s}$. On the other hand, friction for a-C:H decreased slowly to around 0.045 and did not reach the superlow regime, as shown in Fig. 3. This friction result was obtained by almost the same manner for the second test. After the tests, the remaining lubricant and any wear debris on the cylinders and discs were removed by ultrasonic

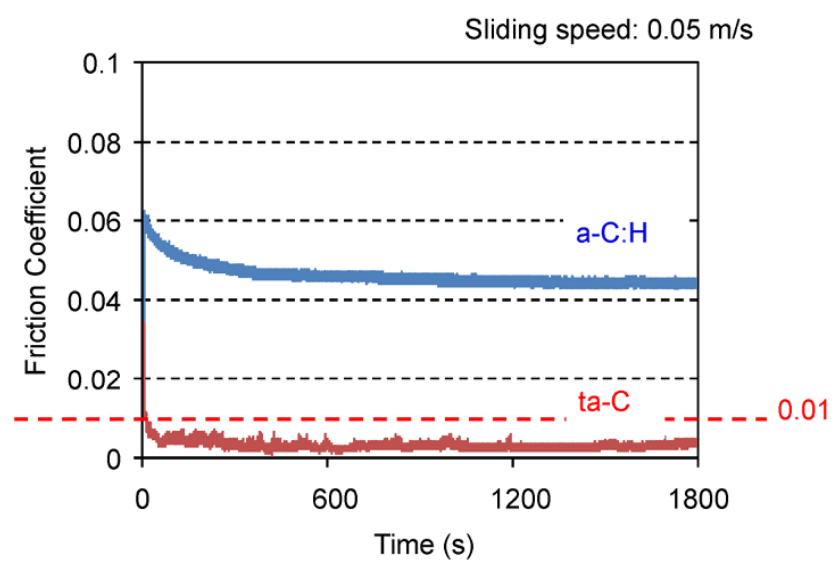

Fig. 3 Superlow friction of ta-C friction pairs lubricated by oleic acid at ambient temperature. cleaning with isopropyl alcohol. One sample was dedicated for ToF-SIMS analysis and the other one was used for angle-resolved XPS (AR-XPS) analysis.

The optical images of the sliding surfaces in Fig. 4 show that all DLC coatings on discs and cylinders are not delaminated although wear on cylinders was more severe than that observed on discs, in agreement with the large difference of kinematic lengths. Indeed, the width of the wear scar on the ta-C coated cylinder is twice smaller than the one on a-C:H. However it appears as coloured in optical microscopy.

The combined surface roughness of $\mathrm{Rq}$ for the cylinder and disc in the sliding track and out of track is also shown in Fig. 4. The large increase of Rq inside the wear scar was not observed for the two types of DLC, which is consistent with the relatively smooth sliding surface shown by scanning electron microscope (SEM) in Fig. 5. The slight increase of surface roughness compared to pristine samples suggested that the ultra-low friction for a-C:H and the super low friction for ta- $C$ were not generated by running-in effect. The almost same surface roughness for DLCs after the sliding test cannot explain the large difference between friction coefficients that is observed in Fig. 3. Therefore, changing of surface roughness does not seem to affect the friction property.

Additionally, it was observed that DLC layers remained perfectly and were not delaminated in the contacting zone although the thickness of them decreased by around $10 \%$ as shown in SEM images in Fig. 5.

The observation of the residual lubricant on the disc after removing the cylinder is interesting (Fig. 6). In the case of a-C:H, oleic acid does not wet the surface,
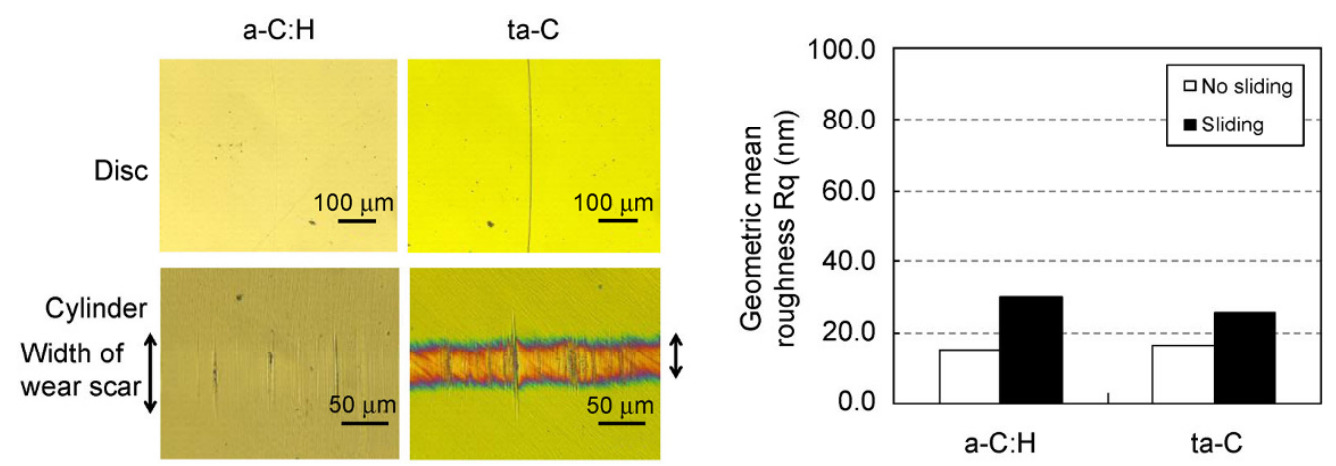

Fig. 4 Optical images of wear scar and combined surface roughness after sliding tests with oleic acid. 

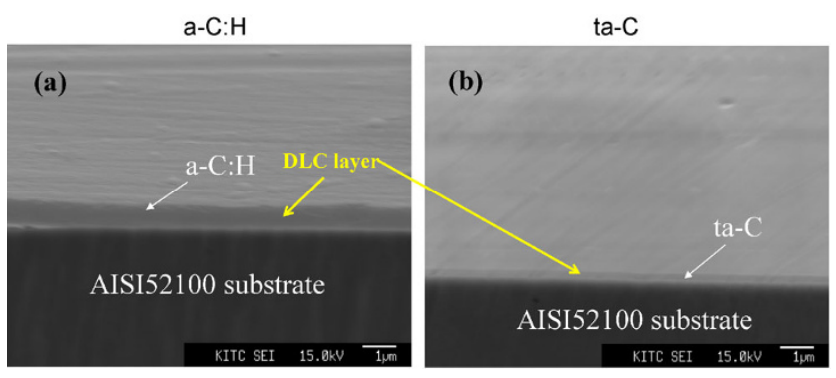

Fig. 5 SEM images of cross-section for cylinder inside wear scar (case of oleic acid).
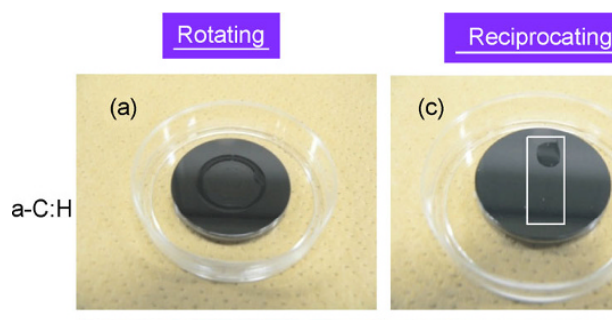

(Another test)
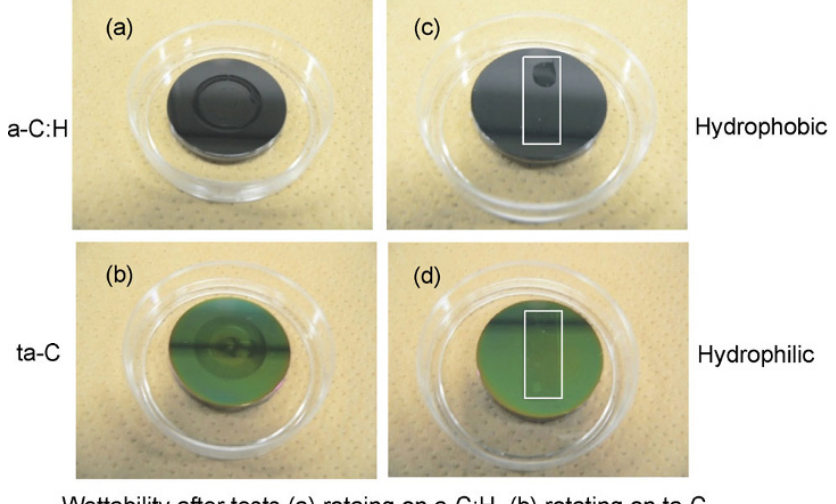

Wettability after tests (a) rotaing on $\mathrm{a}-\mathrm{C}: \mathrm{H}$, (b) rotating on ta- $\mathrm{C}$

(c) reciprocating on a-C: $\mathrm{H}$, (d) reciprocating on ta- $\mathrm{C}$

Fig. 6 Wettability of oleic acid on discs after sliding tests (white rectangle is the wear scar shape).

which is hydrophobic whereas in the case of ta-C the lubricant wets perfectly the surface, this meaning that the worn area has become hydrophilic. This effect is even more visible with the same test conducted with a reciprocating cylinder-on-plane friction machine (see Fig. 6 on the right). Then, the origin of the different performances on the sliding surfaces between ta- $\mathrm{C}$ and a-C:H at constant sliding test of $0.05 \mathrm{~m} / \mathrm{s}(50 \mathrm{~mm} / \mathrm{s})$ under oleic acid lubrication was investigated by surface analysis.

\subsection{Surface analysis on sliding track}

Angle-resolved XPS analysis was performed on both wear scars on the discs. The size of the analyzed area was $2 \mathrm{~mm} \times 0.8 \mathrm{~mm}$ and the location was fixed in the centre in the width of the sliding track. Two angles were selected: $30^{\circ}$ corresponding to a maximum thickness probed of about $3.5 \mathrm{~nm}$ and $80^{\circ}$ corresponding to about $7 \mathrm{~nm}$. Here we only show normalized intensities of selected photopeaks for a-C:H and ta-C (see Fig. 7).
The contribution of $\mathrm{C}$ 1s peaks of carboxylic group $(\mathrm{O}-\mathrm{C}=\mathrm{O})$ is well visible for ta- $\mathrm{C}$ coatings, suggesting that oleic acid molecules have not been completely removed by the cleaning procedure before analysis. However, it is interesting to see that the $C$ 1s photopeaks also contain other contributions like alcohol $(-\mathrm{C}-\mathrm{OH})$ and ketone chemical functions $(>\mathrm{C}=\mathrm{O})$, which are not present in the pristine lubricant. The analysis of DLC by XPS is problematic because it contains only carbon and oxygen and hydrogen cannot be seen. Moreover, XPS can hardly distinguish between sp2 and sp3 hybridization of carbon and the binding energies of the different contributions $(\mathrm{C}-\mathrm{OH}, \mathrm{C}=\mathrm{O}, \mathrm{C}(\mathrm{O}) \mathrm{OH}$, etc.) have not exact values and fluctuates depending on the references taken in the literature. This is the reason why we did not show the decomposition of the $\mathrm{C} 1 \mathrm{~s}$ photopeak. For ta-C coating, these contributions are better visible at the outermost surface. This result supports that a tribochemical reaction between DLC and oleic acid has been generated preferentially at the top surface of the coatings. Moreover, the chemical composition of a-C:H surface is the same whatever the depth probed by the two angles. At the opposite, the ta-C surface is enriched in oxidized species at the very top surface (maximum thickness probed $3 \mathrm{~nm}$ in this case).

The low shear strength tribofilm formation at the boundary lubrication condition (OH-termination) can explain the superlow friction in this regime $[9,10]$. Because the analysis by XPS has a small spatial resolution and cannot give accurate molecular information,

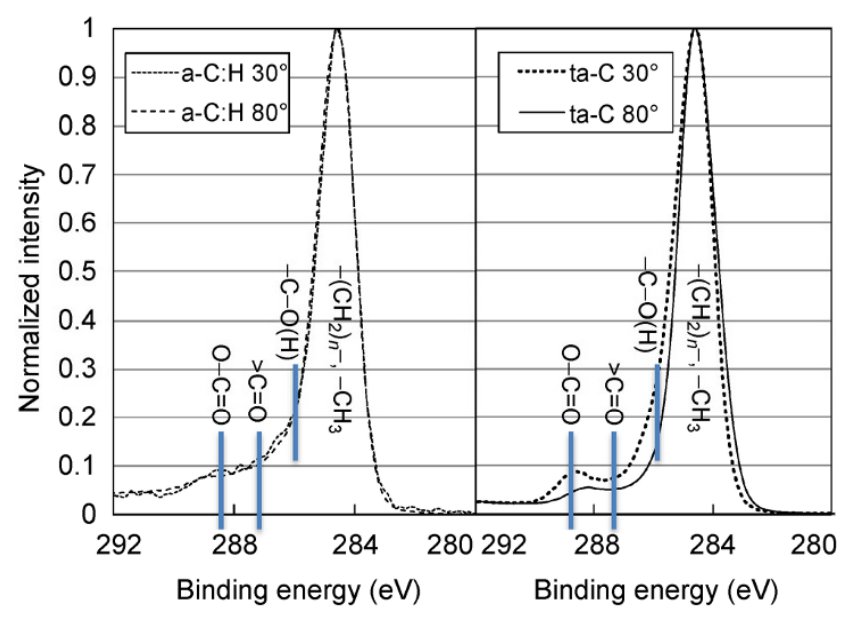

Fig. 7 C 1s XPS spectra recorded inside wear scar on ta-C and a-C:H inside wear scar at two take-off angles. 
SIMS was performed at almost the same position on the surface of the disc (but coming from the second sliding test performed under the same conditions). Selected static ToF-SIMS images on the sliding tracks for a-C:H and ta-C discs are displayed in Fig. 8.

The ion maps are reconstructed from SIMS spectra acquired for each pixel of the scanned zone. In the figures the intensity in the images correspond to the number of the selected molecular ions in spectra obtained from each pixel of the image $\left(\mathrm{CH}^{-},{ }^{2} \mathrm{H}^{-}\right.$, $\mathrm{C}_{17} \mathrm{H}_{33} \mathrm{COO}^{-}$and $\mathrm{COH}^{-}$). Typically, black is no signal and yellow is high intensity of ions. In the images, we notice that the worn surface is not perfect and has the flat part of the plateau shape of the cylinder (drew in white in oleic acid image) with around $5 \mathrm{~mm}$ length and with a few microns height. This distance between the edges fitted well with that of the two rings in the images. Judging from this result, the ring images of ToF-SIMS seemed to be formed by the tribochemical reaction occurring only in the real contacting part of the linear contact. The centre and the corners of the image, which is not in contact with the cylinder, show what happened outside the wear scar. The XPS analyses were performed at a distance of $7 \mathrm{~mm}$ from the centre of the disc and this corresponds to the location of the outer bright ring in the SIMS images. However, because the size of the XPS probe is $2 \mathrm{~mm} \times$ $0.8 \mathrm{~mm}$, it is possible that the signal contains some oleic acid contribution originating from the non-contacting areas. These negative SIMS ions images can be interpreted as follows (see schematic Fig. 8).

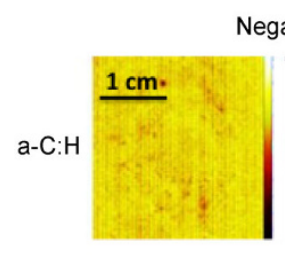

$\mathrm{CH}^{-}$

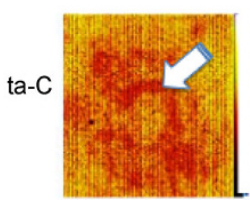

Negative ions ToF-SIMS images on discs

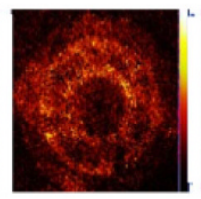

${ }^{2} \mathrm{H}^{-}$

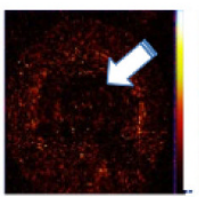

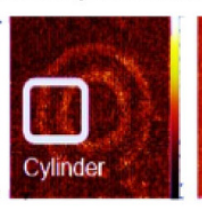

$\mathrm{C}_{17} \mathrm{H}_{33} \mathrm{COO}^{-}$

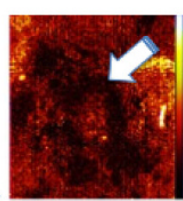

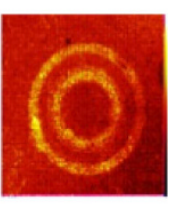

$\mathrm{COH}^{-}$

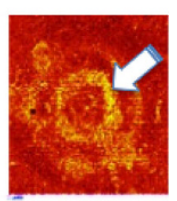

Fig. 8 ToF-SIMS images (negative ions) recorded on sliding tracks for a-C:H and ta-C in the presence of oleic acid.
In the case of a-C:H coating, the image of $\mathrm{CH}^{-}$ shows a quite uniform bright signal and this is characteristic of the H-termination of the DLC and of the presence of about $20 \%$ atomic of hydrogen in the bulk of the coating. However, looking more carefully, it appears that the two rings contain even more hydrogen than outside the track. The similarities of signal intensities in the four images $\mathrm{CH}^{-},{ }^{2} \mathrm{H}^{-}$, $\mathrm{C}_{17} \mathrm{H}_{33} \mathrm{COO}^{-}$and $\mathrm{COH}^{-}$strongly suggest that oleic acid is chemisorbed in the wear scar and not outside. Therefore, in this set of images, $\mathrm{CH}^{-}, \mathrm{COH}^{-}$and ${ }^{2} \mathrm{H}^{-}$ ions are considered as fragments of the parent molecule $\mathrm{C}_{17} \mathrm{H}_{33} \mathrm{COO}^{2} \mathrm{H}^{-}$which is attached to the modified a-C:H surface. As a consequence, the surface terminated by methyl group is not well wetted by the acid, as observed after the test (Figs. 6(a) and 6(c)).

In the case of ta-C, the situation is very different. Even if the images are superimposed to some contamination signal in this case, careful examination of the inner ring on the track (see white arrow) shows that the sliding areas contain very low quantities of $\mathrm{CH}^{-},{ }^{2} \mathrm{H}^{-}$, and $\mathrm{C}_{17} \mathrm{H}_{33} \mathrm{COO}^{-}$ions but they give a clear signal of $\mathrm{COH}^{-}$ions. Therefore, the $\mathrm{COH}^{-}$signal for ta- $\mathrm{C}$ is believed to originate of the tribochemical reaction of oleic acid with $\mathrm{sp}^{2}$-hybridized carbon atoms that was accelerated at the high contact pressure on both edge parts of the apparent contact area of the cylinder. Moreover, the $\mathrm{OH}$-termination does not come from the $\mathrm{O}^{2} \mathrm{H}$ part of the acid group, indicating that the reaction involves the whole molecule. Then, the surface becomes hydrophilic, in agreement with wetting observations at the end of the test test (Figs. 6(b) and 6d). Because the interaction between the $\mathrm{OH}$-terminated surface and oleic acid is mainly hydrogen bonding, the molecules are easily removed by the cleaning procedure before analysis.

From this ToF-SIMS study, it is shown that the tribochemical reaction of ta-C with oleic acid is completely different than that of a-C:H and that the difference in friction coefficient (see Fig. 3) can be attributed to the different surface terminations. We remind here that the analytical depth in ToF-SIMS in the static mode is usually less than $1 \mathrm{~nm}$ and that the signal concerns specifically the molecules lying on the extreme surface. 


\section{Conclusion}

Friction tests have been carried out on bearing steel samples coated with a-C:H and ta-C, under lubricated conditions with 1-hexadecen and pure oleic acid, respectively. Results are summarized in the following.

(1) In the "decreasing sliding speed" test under lubrication regimes varying from the mixed to the boundary conditions, results show very different friction properties for a-C:H and ta-C. The results clearly show that a-C:H is better lubricated by alkenes (probably due to hydrogen release from the double bond) at the opposite of ta- $\mathrm{C}$ that prefers oxygencontaining species in the lubricant.

(2) The friction coefficient for ta-C under oleic acid lubrication showed ultra low friction of around 0.05 below sliding speed of $1 \mathrm{~mm} / \mathrm{s}$ and super-low friction values of around 0.005 above the sliding speed of $50 \mathrm{~mm} / \mathrm{s}$. On the other hand, that for a-C:H showed higher value of 0.1 and 0.02 for each sliding speed range.

(3) The friction coefficient for ta- $\mathrm{C}$ under oleic acid at $50 \mathrm{~mm} / \mathrm{s}$ at constant speed showed super-low value of around 0.005 whereas that for a-C:H showed much higher value of around 0.045 .

(4) In the "constant sliding speed test", it was found very different chemical compositions of the tribofilm formed in the sliding track for a-C:H and ta-C. In the case of oleic acid, surface analyses were performed on the sliding tracks by coupling ToF-SIMS and AR-XPS. Results support that the tribochemical reaction between ta- $C$ and oleic acid is generated preferentially at the top surface with the result of the $\mathrm{OH}$-termination whereas the reaction with a-C:H is more complex. This result gives an explanation to the better wettability observed for oleic acid on the top surface of the sliding surface of ta-C.

(5) In the case of a-C:H coating, the similarities of signal intensities in the four SIMS images $\mathrm{CH}^{-},{ }^{2} \mathrm{H}^{-}$, $\mathrm{C}_{17} \mathrm{H}_{33} \mathrm{COO}^{-}$and $\mathrm{COH}^{-}$strongly suggest that oleic acid is chemisorbed in the wear scar and not outside. This gives an explanation to the fact that oleic acid does not wet the sliding area in this case because alky chains terminate the surface. Therefore, the friction property is similar to the steel/steel case. Moreover, the XPS data show that the tribofilm is thicker than for ta-C.

Open Access: This article is distributed under the terms of the Creative Commons Attribution License which permits any use, distribution, and reproduction in any medium, provided the original author(s) and source are credited.

\section{References}

[1] Mabuchi Y, Hamada T, Izumi H, Yasuda Y, Kano M. The development of hydrogen-free DLC-coated valve-lifter. SAE Paper 2007-01-1752 (2007)

[2] Okuda S, Dewa T, Sagawa T. Development of 5W-30 GF-4 fuel-saving engine oil for DLC-coated valve lifters. SAE Paper 2007-01-1979 (2007)

[3] Yasuda Y, Kano M, Mabuchi Y, Abou S. Research on diamond-like carbon coatings for low-friction valve lifters. SAE Paper 2003-01-1101 (2003)

[4] Kano M, Yasuda Y, Mabuchi Y, Ye J, Konishi S. Ultra-low friction properties of DLC lubricated with ester-containing oil-Part1: Pin-on-disc and SRV friction tests. In 30th LeedsLyon Symposium Proceedings, Lyon, France, 2003: 689-692.

[5] Kano M, Yasuda Y, Okamoto Y, Mabuchi Y, Hanada T, Ueno T, Ye J, Konishi S, Takeshima S, Martin J M, et al. Ultralow friction of DLC in presence of glycerol monooleate (GNO). Tribol Lett 18(2): 245-251 (2005)

[6] Matta C, Joly-Pottuz L, De Barros Bouchet M I, Martin J M, Kano M, Zhang Q, Goddard III W A. Superlubricity and tribochemistry of polyhydric alcohols. Phys Rev B 78: 085436 (2008)

[7] Kano M, Yoshida K. Ultra low friction of DLC coating with lubricant. J Phys: Conf Ser 258: 012009 (2010)

[8] Takigawa H, Izumi K, Miyamoto R, Sakakibara T. DLC thin film preparation by cathodic arc deposition with a super droplet-free system. Surf Coat Tech 163-164: 368-373 (2003)

[9] Joly-Pottuz L, Matta C, De Barros Bouchet M I, Vacher B, Martin J M, Sagawa T. Superlow friction of ta-C lubricated by glycerol: An electron energy loss spectroscopy study. J Appl Phys 102: 064912 (2007)

[10] De Barros-Bouchet M I, Zilibotti G, Matta C, Righi M C, Vandenbulcke L, Vacher B, Martin J M. Lubrication of diamond by water vapor and hydrogen. Coupling gas phase tribometry and computer works, J Phys Chem C 116(12): 6966-6972 (2012) 


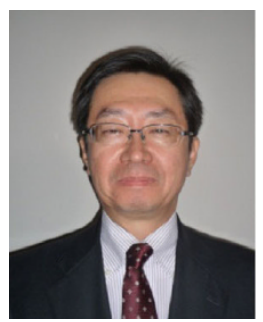

Makoto KANO. He was graduated from the Master course of Metal Engineering of Tokyo Institute of Technology in 1981. He had worked for Nissan Motor Co., Ltd from 1981. He received the $\mathrm{PhD}$ degree in the

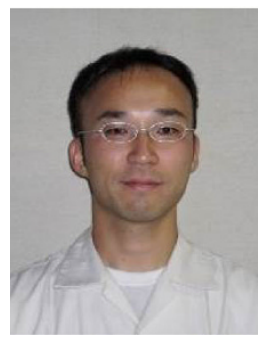

Kentaro YOSHIDA. He received his MS degree in Chemical Engineering in 2000 from Tokyo Institute of Technology, Tokyo, Japan. After then, he worked for the Environmental Laboratory at the Toshiba CO.,

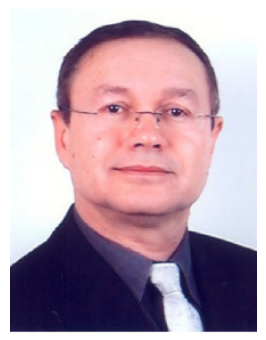

Jean Michel MARTIN. He is a Professor Emeritus at Ecole Centrale de Lyon (University of Lyon, France) since 2011. He obtained his $\mathrm{PhD}$ in 1978 from University of Lyon. He is an honorary member of the University Institute of France (IUF). He has more than 35 years of extensive experience in fundamental and applied research in tribology of thin films, diamondlike coatings, boundary lubrication, mechanical engineering from Tokyo University in 1996. He moved to Kanagawa Industrial Technology Center in 2006. Recent research is focused on reducing friction of sliding parts in automotive engines using DLC coating with the environmentally friendly lubricant.

LTD from 2000. He joined the Material Technology Division at Kanagawa Industrial Technology Center from 2006. His research interests include the tribology of hard coatings and tribo-chemical reaction phenomena with lubricants.

antiwear and extreme-pressure additives, and surface analysis, who discovered superlubricity of pure $\mathrm{MoS}_{2}$ in ultrahigh vacuum and superlubricity of DLC coatings with $\mathrm{OH}$-containing lubricants, implemented new additive formulations for metalforming and engine applications, and developed new analytical techniques for tribofilm analyses (XPS/AES/ToF-SIMS, XANES, etc.). He has published more than 160 papers in tribology, surface analysis and lubricant engineering and possesses 14 patents. 